\title{
State-of-the-art of contactless energy transfer (CET) systems: design rules and applications
}

\author{
RICCARDO TREVISAN $^{1,2}$ AND ALESSANDRA COSTANZO $^{1}$
}

\begin{abstract}
This paper is dedicated to the extensive review of state-of-the-art contactless energy transfer (CET) systems that are gaining increasing interest in the automatic machinery industries. We first introduce the circuit equivalent networks considered in the literature, and discuss the main operating principles. Possible circuital resonant solutions are also discussed together with the required compensating networks. Then we focus on the problem of transferring, at the maximum efficiency, high-power levels (of the order of $1 \mathrm{~kW}$ or higher), showing that highly coupled inductive links are needed, requiring to refrain from the resonance condition. These systems are usually referred to as CET systems, since the link distances are negligible with respect to the coils dimensions. The operating frequencies are of the order of tens to hundreds of kilohertz. The fundamental figures of merit are analytically defined and used to measure the actual limitations involved in this class of systems, including aspects related to realization feasibility with respect to voltages and currents limitations. Finally, state-of-the-art CET works are surveyed, and realistic applications for different operating frequencies are considered and critically compared.
\end{abstract}

Keywords: Contactless energy transfer, Inductive power transfer, Power electronics, Wireless power transfer

Received 15 November 2013; Revised 20 January 2014; first published online 21 March 2014

\section{INTRODUCTION}

Wireless power transfer (WPT) is a major trend of the on-going research in electrical, electronics, and telecommunications sciences. Potential applications cover a wide range of fields, including automotive, energy generation, energy harvesting, bio-medical and industrial [1-6]. The motivations that bear such a broad set of applications are also many and various. In the automotive industry, for example, electric vehicles have a key impact in the next future. Moreover, in many industrial plants the need for contactless delivery of energy to moving loads is currently being almost mandatory since it allows overcoming limitations in terms of performance, reliability, and machinery maintenance due to the presence of sliding contacts or movable power cords. Solutions designed to replace such hardwired joints with contactless energy transfer (CET) links are widely envisaged in literature and stimulated the interest of many industrial activities, as well as numerous research and academic institutions [7-9].

Fortunately, most advances in WPT research can be shared among research groups that work on different topics, thus maximizing the payback of their efforts. Some features, however, require special attentions, and demand for dedicated optimization procedures. Let us consider again the case of

\footnotetext{
${ }^{1}$ Department of Electric and Information Engineering, University of Bologna, Bologna, Italy

${ }^{2}$ IMA Industries Srl, Ozzano dell’Emilia, Bologna, Italy

Corresponding author:

R. Trevisan

Email: riccardo.trevisan2@unibo.it
}

industrial applications. Safety, reliability, and electro-magnetic compatibility (EMC) concerns on manufactured assemblies, for instance, dominate over efficiency and miniaturization issues. Nevertheless, on large-scale production, the feasibility and, more important, the cost of assembled products have a foremost impact. In particular, power applications must seriously take into account absolute maximum ratings of components, such as voltages, currents, and operating temperatures. Furthermore, large safety margins should be considered during the development of a brand-new design. Obviously, these considerations also apply to WPT systems. One of the most common technologies employed in WPT is the inductive power transfer (IPT), which relies on the mutual inductance between coils to deliver electrical power without any physical connection. IPT technology well suits a wide range of applications, which rate from a few milliwatts to several of kilowatts $[10-12]$. For high-power systems, the considerations explained above introduce significant differences in the design of a high-power IPT unit. These include ferromagnetic cores, simplified compensation schemes, lower operating frequencies, and stranded wires, just to cite some examples [13, 14]. As a result, some properties of the IPT device, such as efficiency, geometries, and versatility, are affected. For all these reasons, and in order to account for the different design approaches adopted in power systems, these ones are sometimes named differently, and referred to as CET systems [14-20]. Cited works emphasize the key aspects of the CET system design, including evaluation of magnetic losses, predicted temperatures, and analysis of the external power supply. In fact, a CET application design includes wider aspects than the sole WPT unit modeling. In particular, the power converter behavior is strongly related to the electrical 
description of its load (the WPT device, in this case), and the choice of the optimal topology is not a simple task [21]. For that reason, the power supply design must be considered as a constituent element of the entire CET system.

This paper is dedicated to the review of state-of-the art CET systems from the point of view of both theoretical and technological aspects. First, we address the main design roles that differentiate low-power IPT systems from highpower CET systems. Then we will discuss some popular emerging CET applications, their main subsystem-building blocks and their performance compared to the state-of-the-art CET solutions available in the literature.

The remaining of the paper is structured as follows. Section II first introduces the basics of the IPT technology, describes compensation schemes and its figures of merit; in Section III, the CET technology is presented and the differences with IPT emphasized; considerations on efficiency, compensation, and losses are also discussed in Section III. Section IV is dedicated to the critical evaluation of recent available CET systems, by analyzing their building blocks separately; in the last section we summarize the key points and envisage some future research on the discussed topic.

\section{INDUCTIVEPDWER TRANSFER}

The IPT technology for WPT exploits the variation of the magnetic field flux shared among two or more physically decoupled coils to transfer electric power to one, two, or more loads [11]. Electric transformers are based on inductive coupling too, although are usually designed to transform the voltage, or ensure galvanic separation between circuits, instead of establishing a wireless link for energy transfer.

The widely used equivalent representation of an IPT device is based on coupled inductors, and usually also includes compensating (or resonant) capacitances and winding resistances, as show in Fig. 1.

IPT systems are sometimes referred to as loosely coupled inductive power transfer (LCIPT) systems, in order to emphasize the fact that the coupling $k$,

$$
k=\frac{M}{\sqrt{L_{1} \cdot L_{2}}},
$$

between windings is way far from optimal [22]. As we will show shortly, in these cases the IPT system requires two compensating capacitances $\left(C_{1}, C_{2}\right.$ in Fig. 1$)$ designed to resonate

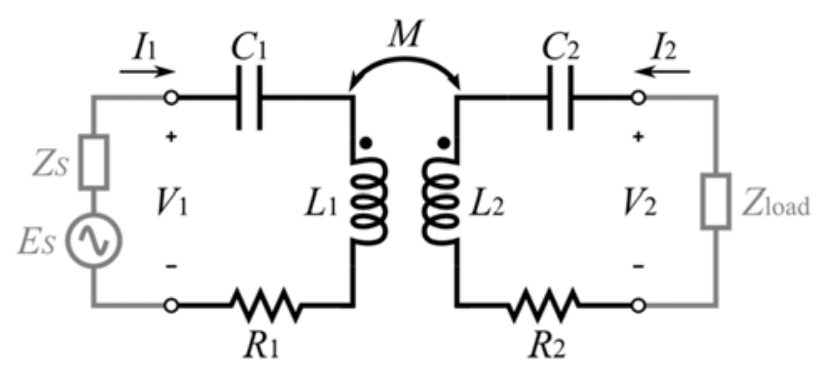

Fig. 1. Power dissipated on the load and IPT device efficiency versus winding inductance $\left(E_{S}=100 \mathrm{~V} ; Z_{S}=0 \Omega ; Q_{1}, Q_{2}=100 ; R_{1,2} \in\left[30 \cdot 10^{-6}, 350\right] \Omega\right.$; $C_{1}, C_{2}$ resonant; $\left.R_{\text {load }}=50 \Omega ; k=0.9 ; M \in\left[9 \cdot 10^{-9}, 9 \cdot 10^{-4}\right] \mathrm{H}\right)$. with the coil inductances $L_{1}, L_{2}$. Coil resistances $R_{1}, R_{2}$ define the $Q$-factors as follows:

$$
Q_{1}=\frac{\omega L_{1}}{R_{1}}, \quad Q_{2}=\frac{\omega L_{2}}{R_{2}},
$$

where $\omega$ is the radian frequency.

\section{A) Compensation}

The main goals in the design of an IPT device are its efficiency and its power transfer capability. As described later in this section, in order to reduce losses in the system and maximize the transferred power, the inductance of the coils needs to be compensated [23]. An optimal compensation can be obtained by adding series or parallel capacitances that resonate with the coil inductances. Depending on the characteristics of the selected IPT devices and the constraints on load and source impedances, the optimal configuration of the compensating network $\left(C_{1}, C_{2}\right.$ in Fig. 1) may vary. In Fig. 2, four possible compensation arrangements are shown. Primary and secondary compensating capacitors $\left(C_{1}, C_{2}\right)$ are placed either in series $(\mathrm{S})$ or in parallel $(\mathrm{P})$ with the respective self-inductance $\left(L_{1}, L_{2}\right)$.

Literature provides several guidelines for choosing the best compensating topology, according to the system constraints, in order to maximize the IPT device efficiency or its power transfer capability, providing reliable values for the electrical quantities. As general rules, we can summarize the following considerations:

- If the load is variable, the system requires series primary compensation, since $C_{1}$ in SS or SP does not depend on $R_{\text {load }}$ [24].

- If the magnetic coupling is variable, the system also requires series secondary compensation, since $C_{1}$ and $C_{2}$ in SS do not depend on $M$ [14].

- If load and coupling are fixed, the best secondary compensating topology can be chosen according to load value and secondary inductance $[22,25]$.

- If the parasitic parallel capacitance of the windings is not negligible, the system requires parallel compensation,

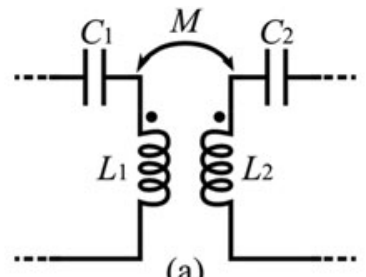

(a)

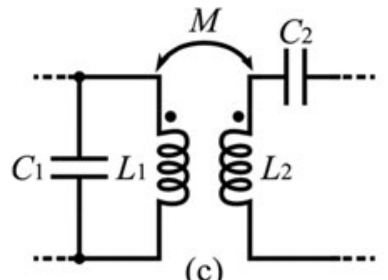

(c)

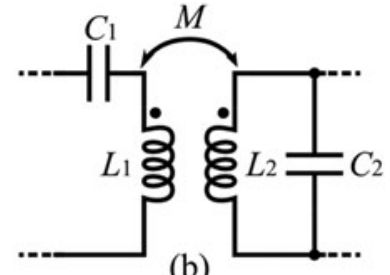

(b)

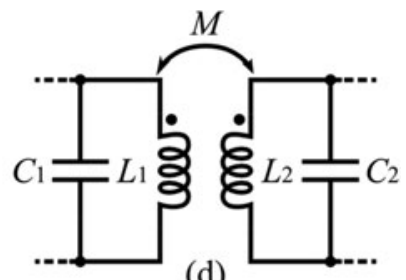

Fig. 2. Efficiency versus magnetising inductance for different coupling coefficients in resonant and non-resonant conditions $\left(E_{S}=100 \mathrm{~V} ; Z_{S}=0 \Omega\right.$; $N_{1}=N_{2} ; Q_{1}, Q_{2}=100 ; R_{1,2} \in\left[30 \cdot 10^{-6}, 350\right] \Omega ; R_{\text {load }}=50 \Omega ; f=50 \mathrm{kHz}$, $\left.R_{\mathrm{m}} \rightarrow \infty\right)$. 
since the parallel resonator can also account for the parasitic capacitance of the coil [26].

- If the real part of the equivalent impedance at the input port of the IPT device is dominated by coil resistances (e.g. dominating winding losses), the system requires parallel compensation, since a parallel capacitance can affect the real part of the equivalent impedance [27].

Although even more complex compensation networks have been studied, such as adaptive matching [9, 28], and additional self-resonant coils $[23,29]$, the SS compensation still represents a widely adopted solution, mainly because of its insensitivity to other parameters such as load and mutual inductance variations [18].

\section{B) Efficiency}

According to the previous paragraph, the expression of the efficiency of an IPT device is not unique, but depends on the adopted compensating network configuration. As said, SS compensation, although sub-optimal for certain cases, represents a robust topology, since capacitances only depend on the windings self-inductances $L_{1}, L_{2}$. Thus, let us consider the IPT device of Fig. 1. Its power efficiency $\eta$ can be expressed as follows:

$$
\begin{aligned}
\eta & =\frac{P_{\text {load }}}{P_{1}}=-\frac{\operatorname{Re}\left[\mathbf{V}_{2} \mathbf{I}_{2}^{*}\right]}{\operatorname{Re}\left[\mathbf{V}_{1} \mathbf{I}_{1}^{*}\right]} \\
& =\frac{R_{\text {load }}}{R_{1} \frac{\left(X_{2}+X_{\text {load }}\right)^{2}+\left(R_{2}+R_{\text {load }}\right)^{2}}{\omega^{2} M^{2}}+\left(R_{2}+R_{\text {load }}\right)},
\end{aligned}
$$

where $X_{2}=\omega L_{2}-1 /\left(\omega C_{2}\right)$, and $Z_{\text {load }}=R_{\text {load }}+j X_{\text {load }}$. Equation (3) shows that the relationship between efficiency and coupling (expressed by $M$ ) as well as between efficiency and resistance of windings $\left(L_{1}, L_{2}\right)$ is not straightforward. Nevertheless, we can infer that primary resonance (or compensation) does not affect the efficiency, whereas secondary resonance (or compensation) and strong coupling improve the efficiency by "compressing" $R_{1}$.

\section{C) Power transfer capability}

In a realistic case, the generator introduces a series impedance $\left(Z_{S} \neq 0 \Omega\right.$, in Fig. 1$)$, which accounts for additional losses. If the source impedance $Z_{S}$ is given, we may be interested into knowing the maximum available power at the output port of the IPT device. In other words, the power transfer capability should be optimized.

As for the SS topology, the maximum output power on the load is expressed by:

$$
\begin{aligned}
P_{\text {load }} & =-\frac{1}{2} \operatorname{Re}\left[\mathbf{V}_{2} \mathbf{I}_{2}^{*}\right] \\
& =\frac{R_{\text {load }}}{2} \frac{\left|E_{S}\right|^{2}}{\left|\frac{\left(Z_{S}+Z_{1}\right)\left(Z_{2}+Z_{\text {load }}\right)}{\omega M}+\omega M\right|^{2}} .
\end{aligned}
$$

In this case, primary and secondary compensations provide a direct advantage in terms of maximum available power at the output port. If we consider purely resistive load and source impedance (i.e. $X_{\text {load }}=X_{S}=0 \Omega$ ), and the coils are resonant (i.e. $\omega=\omega_{0}=1 / \sqrt{L_{1} C_{1}}=1 / \sqrt{L_{2} C_{2}}$ ), equation (4) turns into:

$$
P_{\text {load }}=\frac{R_{\text {load }}}{2} \frac{\left|E_{S}\right|^{2}}{\left|\frac{R_{S} R_{\text {load }}}{\omega_{0} M}+\omega_{0} M\right|^{2}},
$$

and the power transfer capability is maximized. Further improvements can be achieved if the final load is a design parameter and is not given, by differentiating the second term of equation (5) with respect to $R_{\text {load }}$, as explained in [23].

\section{CONTACTLESS ENERGY TRANSFER}

The collection of possible IPT applications covers a wide range of power ratings, from a few milliwatts to several of kilowatts [10-12]. As the requirement on the transferred power increases, the system-operating frequency is limited by the switching speed of the power converter [15]. Figure 3 shows the variations of the output power and of the efficiency with respect to the winding inductances for three configurations of resonant coils at 50,500, and $5 \mathrm{MHz}$, respectively. The $Q$-factor of each coil is held constant (equal to 10), as can be obtained by piecewise optimization of coil and wire geometries, and the winding resistance of each $i$ th-coil computed as

$$
R_{i}=\frac{\omega L_{i}}{Q}, \quad i=1,2, \ldots
$$

according to equation (2).

As expected, as the frequency decreases, the best efficiency is obtained at higher values of inductance. In these cases, air coils may not be sufficient to achieve the required inductance, and ferromagnetic cores become necessary to limit the dimension of the IPT unit and contain winding losses by increasing the $Q$-factor.

In the literature, the distinction between IPT and CET is vague. Some works (e.g. $[30,31])$ refer to CET systems to aggregate different WPT technologies in the same device, such as inductive and capacitive power transfer or simply consider WPT systems based on non-inductive devices. However, the CET term should be adopted in place of the IPT one, to indicate systems characterized by strong magnetic coupling (equal to or greater than 0.8 , often including magnetic

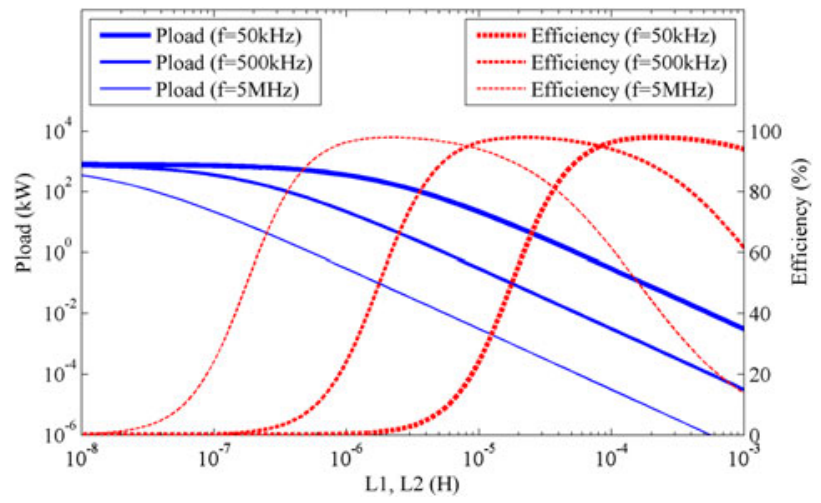

Fig. 3. Power dissipated on the load and IPT device efficiency versus winding inductance $\left(E_{S}=100 \mathrm{~V} ; Z_{S}=0 \Omega ; Q_{1}, Q_{2}=100\left(R_{1,2} \in[30 \mu, 350 \Omega]\right) ; C_{1}, C_{2}\right.$ resonant; $R_{\text {load }}=50 \Omega ; k=0.9\left(M \in\left[9 \times 10^{-9}, 9 \times 10^{-4}\right](\mathrm{H})\right)$. 
cores) and low operating frequency (from 10 to $500 \mathrm{kHz}$ ); this allows high WPT efficiency (usually greater than 70\%), and relatively high-power ratings (e.g. more than a kilowatt) [15, $16,32,33]$. In these cases, the necessity of a contactless transfer of electrical power usually comes from the need of supplying moving parts, such as rotating disks or sliding loads.

The strong coupling and the high $Q$-values of CET systems are mandatory at high powers not only for preserving the system efficiency but, more important, for ensuring protection from the EMI point of view. This can be obtained by combining two technological realizations:

1. Air gap between coils negligible with respect to their dimensions (e.g. less than a tenth of the coil radius);

2. Coils wound on ferromagnetic cores.

The combination of the two features into the same CET device results into the design of an IPT unit that can be also considered as an electrical transformer [7]. Coils, however, can be differently shaped, in order to feature a proper magnetic circuit for the specific application. Although most systems adopt circular coils, rectangular windings are not uncommon [19, 34]. The latters have comparable performance, since at the CET operating frequencies, which lie in the kilohertz range, the conductor edges do not contribute significantly to the overall power losses. The coils shape also defines the geometry of the magnetic core: for circular coils, pot cores are generally employed, whereas for rectangular windings of sliding tracks the core shape can be more arbitrarily chosen. In these cases, E-shaped cores or rectangular blocks of ferromagnetic material can be used to enclose the magnetic flux.

\section{A) Electrical equivalent representation}

Because of the similarity between a CET unit and a transformer, the adopted equivalent electrical representation of the device is usually different from the diagram of Fig. 1, and the $T$-parameter representation visible in Fig. 4 is considered. The leakage inductances $L_{l k_{1}}, L_{l k_{2}}$ and the magnetizing inductance $L_{m}$ are shown instead of the self-inductances $L_{1}, L_{2}$. In addition, the number of turns of coils $N_{1}, N_{2}$, and the resistance $R_{m}$, which accounts for losses in the magnetic core, are shown, whereas the other parameters remain unchanged.

A quick conversion between the CET representation and the IPT representation of a WPT unit is always possible by using equivalences summarized in Table 1 , with the exception of the core resistance $R_{m}$. In some cases, indeed, as for resonance analysis, the IPT diagram is more convenient.

\section{B) Efficiency}

Especially when the power rating of the system becomes considerable, the CET design should maximize the efficiency of

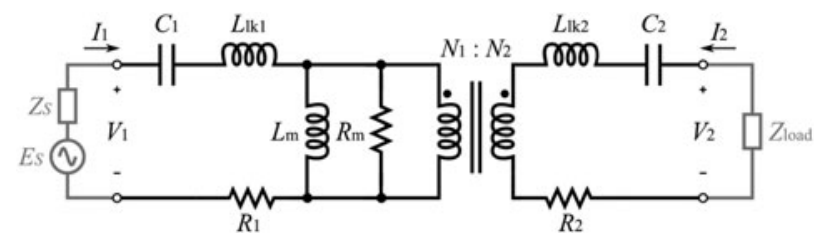

Fig. 4. Electrical equivalent representation of the transformer used to model a CET unit.
Table 1. Conversion expressions between CET and IPT representations.

\begin{tabular}{lll}
\hline IPT parameter & & CET equivalence \\
\hline$L_{1}$ & $=$ & $L_{l k 1}+L_{m}$ \\
$L_{2}$ & $=$ & $L_{l k 2}+\left(\frac{N_{2}}{N_{1}}\right)^{2} L_{m}$ \\
$M$ & $=$ & $\frac{N_{2}}{N_{1}} L_{m}$ \\
\hline
\end{tabular}

the IPT unit, rather than its power transfer capability, in order to contain power losses that contribute to the system self-heating. In literature, analytical expressions of the power transfer capability of a CET unit are quite uncommon indeed, whereas efficiency expressions may assume different forms. Forms based on the $Q$-factors of the coils have the advantage to characterize the system by geometrical and material properties only, although do not implement the dependence on the core resistance $R_{m}$ [35]. Conversely, forms based on the $R$ - and $L$ - parameters of Fig. 4 can include core losses as well $[32,36,37]$. By adopting the compensation topology of Fig. 4, the CET unit efficiency, as defined in equation (3), can be rewritten as

$$
\eta=\frac{R_{\text {load }} n^{2}}{\operatorname{Re}\left[Z_{\text {in }}\right]\left|\frac{\left(R_{\text {load }}+Z_{2}\right) n^{2}}{Z_{m}}+1\right|^{2}}
$$

where

$$
\begin{gathered}
n=\frac{N_{1}}{N_{2}}, \quad Z_{i}=j \omega L_{l k i}+\frac{1}{j \omega C_{l k i}}+R_{i}, \quad i=1,2, \ldots, \\
Z_{m}=\frac{j \omega L_{m} R_{m}}{j \omega L_{m}+R_{m}}, \quad Z_{\text {in }}=Z_{1}+\frac{n^{2}\left(Z_{2}+R_{\text {load }}\right) Z_{m}}{n^{2}\left(Z_{2}+R_{\text {load }}\right)+Z_{m}} .
\end{gathered}
$$

At resonance frequency $\omega_{0}$, equation (7) can be strongly simplified if we suppose $R_{\text {load }} \gg R_{2}$ and neglect core losses. In this particular case, the expression of efficiency turns into

$$
\eta=\frac{1}{1+\left(R_{1} R_{l o a d} n^{2} / L_{m}^{2} \omega^{2}\right)}
$$

Although core losses should not be neglected in a CET unit, equation (9) confirms that strong coupling, combined with the appropriate compensating network, improves the efficiency, as expected.

\section{C) Compensation}

CET systems usually implement capacitive resonance. A high coupling coefficient, however, can partially alleviate the absence of compensation. For example, works presented in $[13,20]$ do not explicitly implement capacitive compensation, thus do not operate at resonance. Figure 5 shows the plots of the efficiency versus the magnetizing inductance for different coupling coefficients in resonant and non-resonant conditions. In these plots, the coils $Q$ factor is held constant; hence, as the inductance increases, the coil resistance increases as well, and the system efficiency begins to decrease after a certain point with a non-symmetrical behavior. 


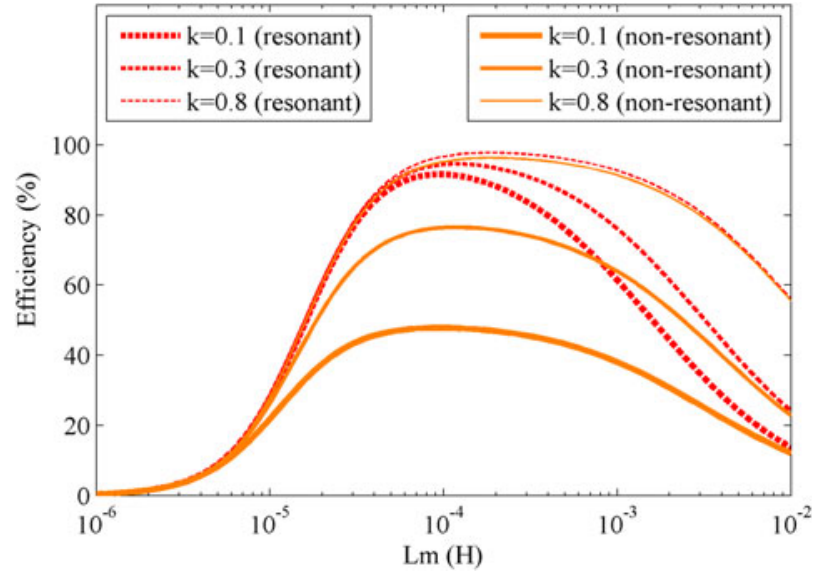

Fig. 5. Efficiency versus magnetizing inductance for different coupling coefficients in resonant and non-resonant conditions $\left(E_{S}=100 \mathrm{~V} ; Z_{S}=0 \Omega\right.$; $N_{1}=N_{2} ; Q_{1}, Q_{2}=100\left(R_{1,2} \in[30 \mu, 350 \Omega]\right) ; R_{\text {load }}=50 \Omega ; f=50 \mathrm{kHz}$, $\left.R_{m} \rightarrow \infty\right)$

As can be noted, as the mutual coupling increases, the difference in terms of efficiency between the resonant (compensated) and non-resonant (not compensated) cases becomes smaller. Therefore, a non-resonant design should be considered. In fact, for certain values of inductance and current ratings, the voltage levels across the corresponding resonant capacitor terminals may result prohibitive. To quantify this, we can compute the voltage magnitudes $V_{C}$ across capacitor $C_{1}$, under resonance conditions and $N_{1}=N_{2}$, as:

$$
V_{C}=\frac{E_{\mathrm{S}}}{k\left(R_{1} / \omega L_{m}+\omega L_{m} / R_{2}+R_{\text {load }}\right)} .
$$

The corresponding behavior is plotted in Fig. 6, versus the magnetizing inductance, for different source voltages (100, 200 , and $300 \mathrm{~V}$ ) and fixed windings resistance. Fixed resistances can be easily obtained by increasing the conductors effective section. In this case, a symmetrical behavior is observed, since the $Q$ factor varies with the inductance.

At $50 \mathrm{kHz}$, the resonant capacitance for a magnetizing inductance equal to $20 \mu \mathrm{H}$ is approximately $500 \mathrm{nF}$. Commercial capacitors of such values can difficultly rate

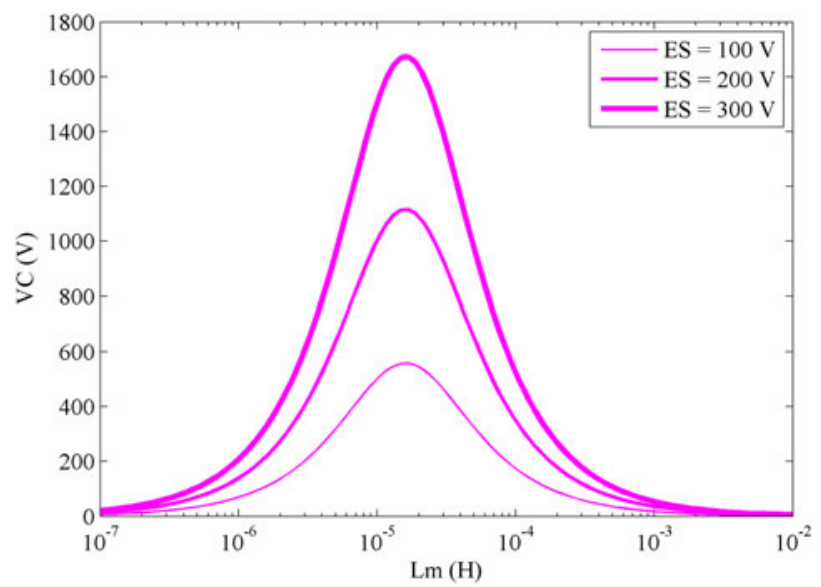

Fig. 6. Voltage magnitude across capacitor $C_{1}$ versus magnetizing inductance for different source voltages $\left(Z_{S}=0 \Omega ; N_{1}=N_{2} ; k=0.9 ; R_{1}, R_{2}=0.5 \Omega\right.$; $\left.R_{\text {load }}=50 \Omega ; f=50 \mathrm{kHz}, R_{m} \rightarrow \infty\right)$. more than a few hundred volts, whereas the computed voltage is well above $1500 \mathrm{~V}$. For this reason, as far as the power factor of the CET unit is not a concern, is not unusual to design high-power IPT systems way far from their resonant frequencies.

\section{D) Losses}

Power losses in CET systems cannot be neglected. Although efficiencies of CET units are often above $90 \%$, a few tens of dissipated watts are enough to increase the device temperature to warning levels and put the whole system reliability in jeopardy. Three main factors are responsible for power losses in a CET unit: skin effect and proximity effect in windings, and eddy currents in the core.

\section{1) WINDING LOSSES}

The first parasitic element considered is the well-known skin effect, which results in an increase in the wire resistance when ac currents at higher frequencies circulate through them. The skin depth $\delta$ is defined as the depth below the surface of the conductor at which the current density $J$ has fallen to $1 / e$ of the current density at the surface $J_{S}$. In round conductors, it is well approximated as:

$$
\delta=\sqrt{\frac{2 \rho}{\omega \mu}}
$$

where $\rho$ is the resistivity of the conductor, $\omega$ is the angular frequency of current, and $\mu$ is the absolute magnetic permeability of the conductor.

Wires stacked in layers, the ones above the others, also suffer from the proximity effect that contributes to reduce the effective wire current cross-section due to the induced magnetic field from adjacent conductors [38]. Many works estimate the equivalent ac resistance of windings in magnetic components, when skin effect and proximity effect losses are considerable, such as $[39,40]$. Generally, a strong reduction of these effects is obtained by adopting stranded wire, also called litz wire. Sullivan in [41] proposes a method to optimize the number of strands in a litz wire, by considering wire's thickness as well as core's geometries. Given the dc resistance of the winding, $R_{d c}$, its $d c+a c$ resistance can be estimated as follows:

$$
R_{a c+d c}=R_{d c}\left(1+\frac{\pi^{2} \omega^{2} \mu_{o}^{2} N^{2} n^{2} d_{c}^{6} \gamma}{768 \rho_{c}^{2} b_{c}^{2}}\right)
$$

In equation (12), the current is supposed sinusoidal and $\omega$ is the radian frequency, $n$ the number of strands, $N$ the number of turns, $d_{c}$ the diameter of the copper in each strand, $\rho_{c}$ the resistivity of the copper, $b_{c}$ the breadth of the window area of the core, and $\gamma$ a factor accounting for nonuniform field distribution in windings, usually equal to one.

Hence, electrical losses of windings, $P_{\text {loss, },}$, can be computed as follows:

$$
P_{l o s s, e}=\frac{1}{2}\left|I_{1}\right|^{2} R_{1}+\frac{1}{2}\left|I_{2}\right|^{2} R_{2} .
$$

\section{2) CORE LOSSES}

Core losses represent a considerable portion of the total losses of a CET unit. The choice of the material employed as 
ferromagnetic core is essential to prevent an excessive selfheating and ensure high efficiency. The frequency range of CET systems (usually $20-200 \mathrm{kHz}$ ) demands for highresistivity ferromagnetic materials, in order to prevent the circulating of strong eddy currents within the core. Soft ferrites are commonly employed in the frequency range of interest because, despite the lower point of magnetic saturation compared to steel, their high resistivity significantly reduces those parasitic currents. Eddy currents and magnetic hysteresis, both proportional to the $\mathbf{B}$-field (or magnetic flux density), are responsible for magnetic core losses $P_{\text {loss }, m}$ within the core. An approximate computation of $P_{\text {loss }, m}$, which includes eddy currents and magnetic hysteresis contributes, is possible thanks to the Steinmetz's equation [42]:

$$
P_{\text {loss }, m}=C_{m} C(T) f^{x} \hat{B}^{y} V_{e},
$$

where $V_{e}$ is the effective volume of the core, $\hat{B}$ the peak flux density of a sine wave at frequency $f, C_{m}, x, y$ material constants, and $C(T)$ a temperature correction factor. Such parameters can be derived from materials data sheets or retrieved from available surveys $[43,44]$. The peak flux density can be calculated by estimating the magnetizing current $i_{m}$, or computing the current $i_{m}$ iteratively, due to the dependence of $R_{m}$ on $P_{\text {loss }, m}$. The relation between $B$ and $i_{m}$ is not immediate. However, as explained in [45], it can be expressed and approximated (if $L_{l k_{1}}$ is sufficiently small) as:

$$
\hat{B}=\frac{L_{m}}{N_{1} A_{e}} \hat{\imath}_{m} \approx \frac{\hat{V}_{1}}{\omega N_{1} A_{e}},
$$

where $\hat{\iota}_{m}$ is the magnetizing current peak and $A_{e}$ the effective area of the core. Computed $P_{\text {loss }, m}$, the core resistance $R_{m}$ can be approximated by neglecting the leakage inductance $L_{l k_{1}}$ as:

$$
R_{m}=\frac{1}{2} \frac{\left|V_{1}\right|^{2}}{P_{l o s s, m}} .
$$

From equations (13) and (14) we can straightforwardly evaluate the loss ratio as:

$$
R_{\text {loss }, i}=\frac{P_{\text {loss }, i}}{P_{\text {out }}}, \quad i=m, e .
$$

In Fig. 7 , these quantities are plotted versus number of turns for a constant output power ( $900 \mathrm{~W})$ at two different frequencies, 50 and $100 \mathrm{kHz}$. The ferrite core considered in the analysis is a ${ }^{\circledR}$ Ferroxcube ${ }_{3} \mathrm{C} 81$ P66 pot core [46].

From the picture it is evident how the computation of the optimal trade-off among several design parameters, such as number of turns, frequency, and core type, is not immediate ad may require to be evaluated iteratively.

\section{CET SYSTEMS}

Figure 8 shows an overview of a CET system, represented by several building blocks.

In a CET system, the primary source of energy is usually the mains. A switching-mode power supply is used to convert the mains frequency up to tens of $\mathrm{kHz}$ and acts as power transmitter for the WPT link. The inductive CET

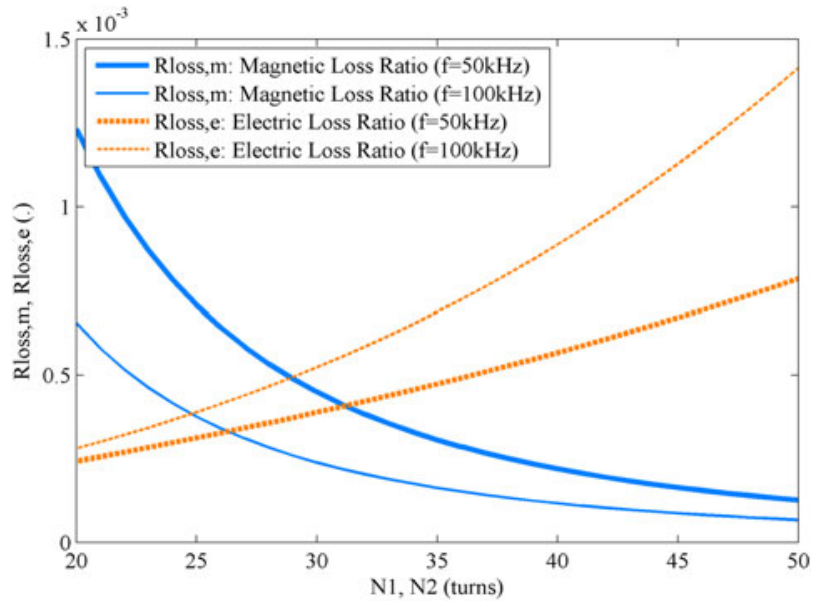

Fig. 7. Comparison between core and winding loss ratios versus number of turns at different frequencies for a constant output power $\left(V_{2}=300 \mathrm{~V} ; \mathrm{C} 1\right.$, $\mathrm{C}_{2}$ resonant; $R_{\text {load }}=50 \Omega ; k=0.9$; coil radius $=18.5 \mathrm{~mm}$; coil resistance per unit of length $=9.7 \mathrm{~m} \Omega / \mathrm{m}$; strands number $=50$; strand diameter $=$ $0.1 \mathrm{~mm}$; core window breadth $=10.6 \mathrm{~mm}$; core reluctance $=9.8 \times 10^{-5}$ turns ${ }^{2} / \mathrm{H}$; ferrite $={ }^{\circledR}$ Ferroxcube $3 \mathrm{C} 91$; effective area $=717 \mathrm{~mm}^{2}$; effective volume $\left.=88200 \mathrm{~mm}^{3}\right)$.

unit (i.e. a contactless transformer, in this case) constitutes the WPT link and the power receiver is often represented by an ac/dc power converter, or rectifying stage. Sometimes, the ac/dc conversion is unnecessary, and the final load is directly connected to the WPT link and represents the power receiver itself.

\section{A) Power transmitter}

In order to contain the size of the magnetic core, thus preventing its saturation, the mains $50-($ or $60-) ~ H z$ voltage should be switched at a higher frequency. The direct generation of a pure sine wave is almost impossible at power ratings of CET systems. In these cases, the widely employed solution is represented by switching mode power supplies (SMPS). The state-of-the-art SMPS adopt soft-switching techniques in order to alleviate turn-on and turn-off losses of the switching network, theoretically extending the devices lifetime and avoiding possible electromagnetic interference (EMI) [47, 48]. Soft-switching techniques rely on inductive loads to achieve zero-voltage or zero-current commutation of the switches $[49,50]$. For high-power and high-frequency operation, zero-voltage switching (ZVS) converters are preferred over zero-current switching (ZCS) ones, because the parasitic elements of switching components facilitate the soft-switching mechanism [51].

The presence of an inductive element (i.e. WPT link) suggests that the contactless transformer itself can be used to store the energy controlled by the converter. Authors of [21], for

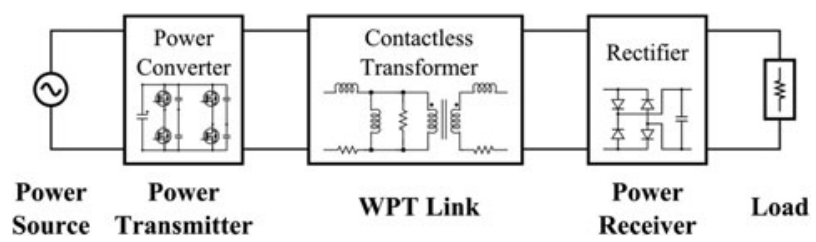

Fig. 8. Overview of a CET system. 
Table 2. CET systems comparison.

\begin{tabular}{|c|c|c|c|c|c|c|c|}
\hline Converter topology & $f(\mathbf{k H z})$ & $P_{\text {load }}(\mathrm{W})$ & CET geometry & $\operatorname{Max} k()$. & $\operatorname{Max} \eta(\%)$ & Output rectifier & Ref \\
\hline Resonant full-bridge & 30 & $\mathrm{~N} / \mathrm{A}$ & Linear track & 0.8 & $\mathrm{~N} / \mathrm{A}$ & Four-diode bridge & [6] \\
\hline Half-bridge & 191 & 33 & Planar array* & 0.3 & 89 & Four-diode bridge & [52] \\
\hline ZVS full-bridge & 100 & 1000 & Rotary transf. & $>0.9$ & $\mathrm{~N} / \mathrm{A}$ & Two diodes, central tap & [21] \\
\hline Resonant half-bridge & 30 & 20 & Linear track* & 0.2 & $76 \dagger$ & Four-diode bridge & [53] \\
\hline Resonant full-bridge & 90 & 1000 & Rotary transf. & 0.8 & 82 & Two diodes, central tap & [17] \\
\hline ZCS full-bridge & 60 & 3000 & Rotary transf. & 0.8 & $93 \dagger$ & Four-diode bridge & [14] \\
\hline Resonant full-bridge & 165 & 1000 & Sliding transf. & N/A & $95 \dagger$ & Four-diode bridge & \\
\hline ZVS/ZCS full-bridge & 100 & 1600 & Gapped transf. & 0.8 & $94^{\dagger}$ & Four-diode bridge & [20] \\
\hline ZVS full-bridge & 50 & 1000 & Rotary transf. & 0.9 & 98 & None & [37] \\
\hline
\end{tabular}

*Not a proper CET system (as intended in this work) due to the weak coupling.

$\dagger$ Includes power electronics efficiency.

example, propose a phase-shift ZVS full-bridge converter that exploits the inductive equivalent input impedance of the transformer and four parallel capacitances to achieve soft switching of active elements. Differently, the work presented in [17] introduces primary compensation and exploits this capacitance to realize a resonant tank that eases the resonant process of the converter.

Table 2 shows comparisons of some state-of-the-art CET systems considered in this review. The adopted power converter topologies are shown, as well as system ratings, geometry of magnetic circuits (discussed next), and specifications of power receivers.

\section{B) WPT link}

The WPT link represents the core of the system. In previous paragraphs, we described the theory of operation of a CET unit. In the following, instead, we present two different implementations of the IPT device widely discussed in CET-related literature: the sliding transformer and the rotary transformer.

\section{1) LINEAR TRANSFORMER}

The description of a CET system based on a linear transformer is formally introduced in [32], though studied in numerous other works, such as $[6,53,54]$. A linear transformer, is composed by a linear track that constitutes a long magnetic primary circuit, or a long primary winding loop, and one or more secondary winding wound about a "magnetic pickup" free to move on the linear track, as shown in Fig. 9(a).

As described in $[34,55]$, for example, the sliding transformer can also be intended differently. Authors of cited works propose a sliding transformer in which the primary track is segmented into several primary coils wound about several core blocks, and some secondary pickups that face primary coils along a secondary parallel track, as depicted in Fig. 9(b). This way, magnetic leakage and ohmic losses can be reduced, and the efficiency improved.

Finally, planar array geometry can be derived from the sliding transformer, as proposed in [56]. Similarly to a segmented primary linear track, several primary coils are distributed over a $2 \mathrm{D}$ surface, and a secondary pickup is free to move along two axes.

Typical applications of linear transformers are represented by electrical delivery systems for planar moving platforms. Some examples are drive belts, linearly moving motors, and power rails.

\section{2) ROTARY TRANSFORMER}

A rotary (or rotatable) transformer design represents one of the first implementation of a CET system $[7,12]$. Rotatable transformers are usually based on pot-core ferrite cores. A pot-core transformer is composed by two separate half cores, as shown in Fig. 10.

In a standard application, a pot-core transformer encloses two windings wrapped about its central leg and a through-hole screw, or an external spring, tightens the half cores together. Conversely, pot cores for CET applications exploit the physical separation of the halves to allow the rotation of the one with respect to the other. Physical separation is obtained by ensuring an air gap between the halves.

In order to allow relative rotation, the windings must be detached as well. Two different winding topologies are possible, either adjacent windings or coaxial windings [57]. In the former topology each winding is placed in its own half core, whereas in the latter windings are concentric. Many works compare the two different topologies, e.g. [58]. Depending upon the final application, the one might be more favorable than the other. On the one hand, for example, the adjacent topology exploits
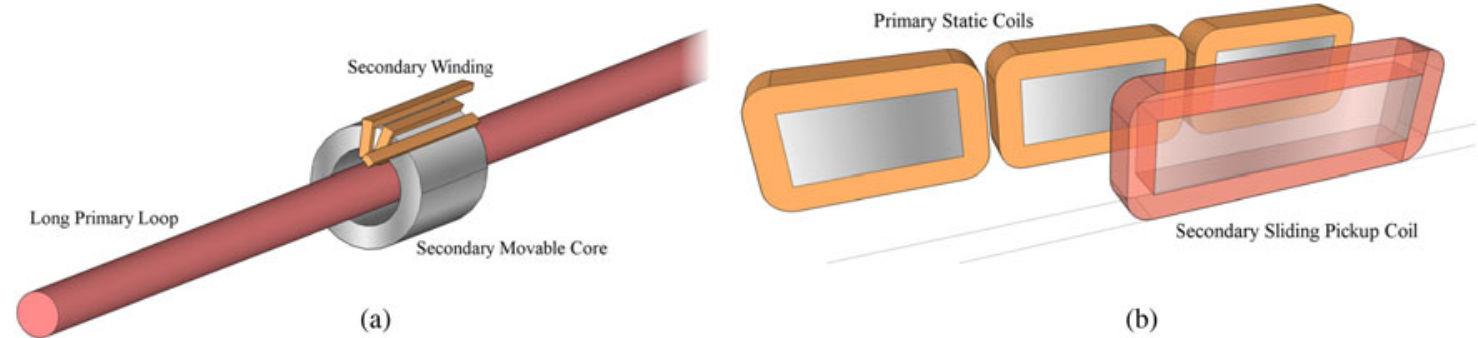

Fig. 9. Three-dimensional (3D) representations of (a) a linear transformer as in [32]; and (b) a sliding transformer as in [34]. 


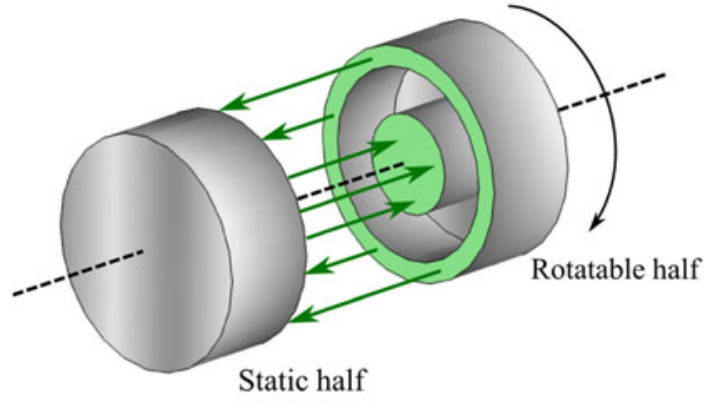

(a)

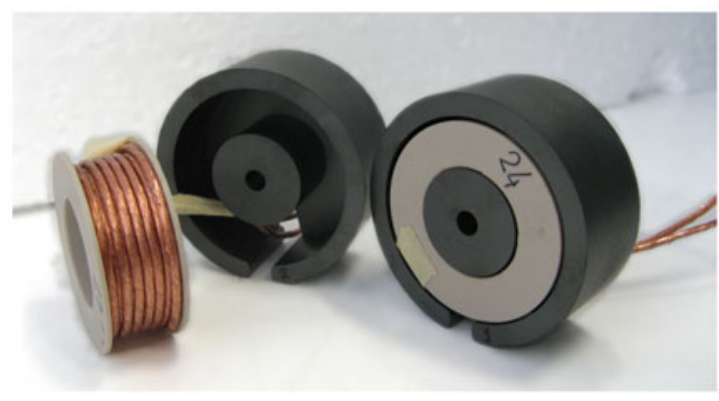

(b)

Fig. 10. (a) Three-dimensional (3D) representation of two half pot cores and their magnetic flux lines as in [37]; (b) prototyped version of a pot-core transformer with air gap as in $[45]$.

the available room for windings in the window area of the core more efficiently, resulting in a lower magnetizing current and, in turn, lower losses. On the other hand, coaxial windings share the whole magnetic flux path of the transformer, resulting in lower leakage inductances and therefore higher coupling coefficient.

Typical applications of rotatable transformers are meant to replace rotary electrical joints, also known as slip rings. Such joints have wide use in both industrial and military areas, for example in robot arms, rotary working tools (as drilling machines, or sealers), and radars. For instance in $[37,45]$, a CET system has been prototyped for power supplying rotatable parts of automatic machineries, namely sealing rollers. The system performance is reported and compared in Table 2. The design of the CET unit is optimized in terms of (i) wires geometries, in this implementation litz wires are adopted to minimize losses; (ii) number of turns; (iii) ferrite type. This way, the optimal trade-off between core and winding losses is realized by adopting analytical analyses presented in Section III.D and numerical simulations. At the stationary side, a power board implements soft-switching techniques, as specified in Table 2, which contributes to further reducing the overall system losses.

\section{C) Power receiver}

The power receiver usually implements a rectifying stage. The $\mathrm{ac} / \mathrm{dc}$ conversion is necessary when the system load operates in the dc regime, such as batteries, logics, or dc drives. In these cases, the rectifier is constituted by a four-diode bridge or, alternatively, a two-diode bridge if the CET unit provides for a central tap. Authors of [59] propose a "reversible rectifier," instead, to allow bidirectional energy flow. Differently, when the system load is resistive, (a heater or a sealer, for example, as in [37]), the ac/dc conversion may be unnecessary if the resulting parasitic load reactance is negligible at the operating frequency.

\section{CONCLUSION}

In this paper, we have provided a deep discussion on the actual performances and challenges of the CET system design. Starting from an equivalent electrical representation of a WPT unit, we have first defined the main figures of merit, in terms of end-to-end efficiency and maximum power that can be transferred. Then we have considered possible combinations of compensating capacitive networks and critically discussed them with respect to the power levels involved. We have shown that the resonant condition of the wireless link is not always the best solution, but the transmitter and receiver mutual coupling needs to be included in such design considerations. We have proposed a formal definition of CET systems, in order to differentiate it from IPT in the context of WPT. In fact, applications that rate more than a kilowatt usually lay in the scope of CET, rather than IPT, because of the stronger coupling and higher inductance values required for reducing power losses and contain the dimensions of the WPT unit. We explained that capacitive compensation may be difficult to be implemented, due to high-voltage levels on capacitors. Thus, because of the tiny disadvantage in terms of efficiency for highly coupled systems, a non-resonant design of the CET device can be considered. On the contrary, power losses represent a major issue on CET units, because of the resulting increase in the device temperature. Seeking optimal trade-off between winding losses and core losses is essential in order to ensure best CET performance and reliability over time. This, however, requires a fine-tuning of several design parameters, such as core geometries, wire choice, frequency, and number of turns.

Finally, we reviewed and compared some state-of-the-art CET systems presented in recent literature. The system key parts, which are power transmitter, WPT link, and power receiver were analyzed separately. In particular, two main WPT link topologies can be found in literature: linear transformer (used with sliding loads) and rotary transformer (used with rotatable loads). Further sub-topologies make the CET system design even more challenging and should be deeply evaluated before prototyping.

Scientific and industrial interest on CET systems is growing, because this technology enables to overcome the severe limitations imposed by sliding or rotatable electrical joints at high-power levels. The scope of CET systems, however, is not limited to power transfer applications. In many cases, one or more feedback signals are required to be sent back from the moving load to the controlling/supplying unit. Therefore, a combined wireless power and information transfer problem arise. Some works already address this issue by combining multiple coils (e.g. power and information windings) in the same core, such as [60]. Other works, as $[6,61]$, propose to modulate the data over the power signal. In either case, the research on CET systems is still far from conclusion, and further challenges are about to arise in the next years. 


\section{ACKNDWLEDGEMENTS}

This work was partly supported by the R\&D department of IMA Industries Srl, Bologna, Italy.

\section{REFERENCES}

[1] Wang, C.-S.; Stielau, O.H.; Covic, G.A.: Design considerations for a contactless electric vehicle battery charger. IEEE Trans. Ind. Electron., 52 (5) (2005), 1308-1314.

[2] Russer, J.A.; Dionigi, M.; Mongiardo, M.; Russer, P.: A moving field inductive power transfer system for electric vehicles, in Proc. 2013 IEEE 43rd European Microwave Conf., Nuremberg, Germany, 2013, 519-522.

[3] Rizzoli, V.; Costanzo, A.; Masotti, D.; Donzelli, F.: Integration of numerical and field-theoretical techniques in the design of singleand multi-band rectennas for micro-power generation. Int. J. Microw. Wireless Technol., 2 (Special Issue 3-4) (2010), 293-303.

[4] Costanzo, A.; Romani, A.; Masotti, D.; Arbizzani, N.; Rizzoli, V.: RF/ baseband co-design of switching receivers for multiband microwave energy harvesting. Sens. Actuators A: Phys., 179 (1) (2012), 158-168.

[5] Ohira, T.: Via-wheel power transfer to vehicles in motion, in Proc. 2013 IEEE Wireless Power Transfer Conf., Perugia, Italy, 2013, 242-246.

[6] Hirai, J.; Kim, T.-w.; Kawamura, A.: Wireless transmission of power and information and information for cableless linear motor drive. IEEE Trans. Power Electron., 15 (1) (2000), 21-27.

[7] Esser, A.; Skudelny, H.-C.: A new approach to power supplies for robots. IEEE Trans. Ind. Appl., 27 (5) (1991), 872-875.

[8] Reinhard, M.; Spindler, C.; Schuer, T.; Birk, V.; Denk, J.: New approaches for contactless power transmission systems integrated in PM motor drives transferring electrical energy to rotating loads, in Proc. 2011 IEEE 14th European Conf. Power Electronics and Applications, Birmingham, UK, 2011, 1-10.

[9] Sample, A.P.; Waters, B.H.; Wisdom, S.T.; Smith, J.R.: Enabling seamless wireless power delivery in dynamic environments. IEEE Proc., 101 (6) (2013), 1343-1358.

[10] Budhia, M.; Covic, G.A.; Boys, J.T.: Design and optimization of circular magnetic structures for lumped inductive power transfer systems. IEEE Trans. Power Electron., 26 (11) (2011), 3096-3108.

[11] Covic, G.A.; Boys, J.T.: Inductive power transfer. Proc. IEEE, 101 (6) (2013), 1276-1289.

[12] Weinberger, S.M.: Preliminary design development of $100 \mathrm{~kW}$ rotary power transfer device, NASA, Technical Report, 1982.

[13] Papastergiou, K.D.; Macpherson, D.E.; Fisher, F.: A 1 kW phase-shifted full bridge converter incorporating contact-less transfer of energy, in Proc. 2005 Power Electronics Specialists Conf., Recife, Brazil, 2005, 83-89.

[14] Moradewicz, A.J.; Kazmierkowski, M.P.: Contactless energy transfer system with FPGA-controlled resonant converter. IEEE Trans. Ind. Electron., 57 (9) (2010), 3181-3190.

[15] Pedder, D.A.G.; Brown, A.D.; Skinner, J.A.: A contactless electrical energy transmission system, IEEE Trans. Ind. Electron., 46 (1) (1999), 23-30.

[16] Papastergiou, K.D.; Macpherson, D.E.: An airborne radar power supply with contactless transfer of energy - Part I: rotating transformer. IEEE Trans. Ind. Electron., 54 (5) (2007), 2874-2884.

[17] Valtchev, S.; Borges, B.; Brandisky, K.; Klaassens, J.B.: Resonant contactless energy transfer with improved efficiency. IEEE Trans. Power Electron., 24 (3) (2009), 685-699.
[18] Kazmierkowski, M.P.; Moradewicz, A.J.: Unplugged but connected: review of contactless energy transfer systems. IEEE Ind. Electron. Mag., 6 (4) (2012), 47-55.

[19] Smeets, J.P.C.; Overboom, T.T.; Jansen, J.W.; Lomonova, E.A.: Comparison of position-independent contactless energy transfer systems. IEEE Trans. Power Electron., 28 (4) (2013), 2059-2067.

[20] Sibue, J.; Kwimang, G.; Ferrieux, J.-P.; Meunier, G.: A global study of a contactless energy transfer system: analytical design, virtual prototyping and experimental validation. IEEE Trans. Power Electron., 28 (10) (2013), 4690-4699.

[21] Papastergiou, K.D.; Macpherson, D.E.: An airborne radar power supply with contactless transfer of energy - Part II: converter design. IEEE Trans. Ind. Electron., 54 (5) (2007), 2885-2893.

[22] Yang, M.; Wang, Y.; Zhang, X.; Li, J.: Analysis of reflected load model for inductively coupled power transfer systems, in Proc. 2010 IEEE AsiaPacific Power and Energy Engineering Conf., Wuhan, China, 2010, 1-4.

[23] Chen, C.-J.; Chu, T.-H.; Lin, C.-L.; Jou, Z.-C.: A study of loosely coupled coils for wireless power transfer. IEEE Trans. Circuits Syst. II, 57 (7) (2010), 536-540.

[24] Wang, C.-S.; Covic, G.A.; Stielau, O.H.: Power transfer capability and bifurcation phenomena of loosely coupled inductive power transfer systems. IEEE Trans. Ind. Electron., 51 (1) (2004), 148-157.

[25] Kiani, M.; Ghovanloo, M.: A figure-of-merit for designing highperformance inductive power transmission links. IEEE Trans. Ind. Electron., 60 (11) (2013), 5292-5305.

[26] Pinuela, M.; Yates, D.C.; Lucyszyn, S.; Mitcheson, P.D.: Maximizing DC-to-load efficiency for inductive power transfer. IEEE Trans. Power Electron., 28 (5) (2013), 2437-2447.

[27] Low, Z.N.; Chinga, R.A.; Tseng, R.; Lin, J.: Design and test of a highpower high-efficiency loosely coupled planar wireless power transfer system. IEEE Trans. Ind. Electron., 56 (5) (2009), 1801-1812.

[28] Waters, B.H.; Sample, A.P.; Smith, J.R.: Adaptive impedance matching for magnetically coupled resonators, in Proc. Progress in Electromagnetics Research Symp. 2012 in Moscow, Moscow, Russia, August 2012, 694-701.

[29] Ahn, D.; Hong, S.: A transmitter or a receiver consisting of two strongly coupled resonators for enhanced resonant coupling in wireless power transfer. IEEE Trans. Ind. Electron., 61 (3) (2014), 1193-1203.

[30] Esser, A.; Nagel, A.: Contactless high speed signal transmission integrated in a compact rotatable power transformer, in Proc. 1993 IEEE Fifth European Conf. Power Electronics and Applications, Brighton, UK, 1993, vol. 4, 409-414.

[31] Theodoridis, M.P.: Effective capacitive power transfer. IEEE Trans. Power Electron., 27 (12) (2012), 4906-4913.

[32] Lastowiecki, J.; Staszewski, P.: Sliding transformer with long magnetic circuit for contactless electrical energy delivery to mobile receivers. IEEE Trans. Ind. Electron., 53 (6) (2006), 1943-1948.

[33] Smeets, J.P.C.; Krop, D.C.J.; Jansen, J.W.; Lomonova, E.A.: Contactless power transfer to a rotating disk, in Proc. 2010 IEEE Int. Symp. Industrial Electronics, Bari, Italy, 2010, 748-753.

[34] Gerrits, T.; Krop, D.C.J.; Encica, L.; Lomonova, E.A.: Development of a linear position independent inductive energy transfer system, in Proc. 2011 IEEE Int. Electric Machines \& Drives Conf., Niagara Falls, ON, 2011, 1445-1449.

[35] Kurschner, D.; Rathge, C.; Jumar, U.: Design methodology for high efficient inductive power transfer systems with high coil positioning flexibility. IEEE Trans. Ind. Electron., 6o (1) (2013), 372-381.

[36] Mecke, R.; Rathge, C.: High frequency resonant inverter for contactless energy transmission over large air gap, in Proc. 2004 IEEE 35th 
Annual Power Electronics Specialists Conf., Aachen, Germany, 2004, vol. $3,1737-1743$.

[37] Trevisan, R.; Costanzo, A.: A 1-kW wireless power transfer link for welding rollers, in Proc. PIERS 2013 in Stockholm, Stockholm, Sweden, 2013, 1566-1570. [Online]. http://piers.org/piersproceedings/ download.php?file=cGllcnMyMDEzU 3 RvY2tob2xtfDRBNF8xNTY2 LnBkZnwxMzAoMTQxMjUxNDU=.

[38] Lotfi, A.W.; Lee, F.C.: A high frequency model for litz wire for switchmode magnetics, in Conf. Rec. 1993 IEEE Industry Applications Society Annual Meeting, Toronto, ON, 1993, vol. 2, 1169-1175.

[39] Dowell, P.L.: Effects of eddy currents in transformer windings. Proc. Inst. Electr. Eng., 113 (8) (1966), 1387-1394.

[40] Ferreira, J.A.: Improved analytical modeling of conductive losses in magnetic components. IEEE Trans. Power Electron., 9 (1) (1994), 127-131.

[41] Sullivan, C.R.: Optimal choice for number of strands in a litz-wire transformer winding. IEEE Trans. Power Electron., 14 (2) (1999), 283-291.

[42] Smeets, J.P.C.; Krop, D.C.J.; Jansen, J.W.; Hendrix, M.A.M.; Lomonova, E.A.: Optimal design of a pot core rotating transformer, in Proc. 2010 IEEE Energy Conversion Congress and Exposition, Atlanta, GA, 2010, 4390-4397.

[43] Steinmetz, C.P.: On the law of hysteresis. Proc. IEEE, 72 (2) (1984), 197-221.

[44] van Horck, F.: A Treatise on Magnetics and Power Electronics, Eindhoven, The Netherlands: Eindhoven Univ. Technol., 2010.

[45] Trevisan, R.; Costanzo, A.: "A 1-kW Contactless Energy Transfer System Based on a Rotary Transformer for Sealing Rollers," IEEE Trans. Ind. Electron, 2014, in press.

[46] Ferroxcube: Soft ferrite and accessories 2009 data handbook. The Netherlands: Ferroxcube International Holding B.V., 2009. [Online]. http://www.ferroxcube.com.

[47] Lu, D.D.-C.; Cheng, D.K.-W.; Lee, Y.-S.: A single-switch continuousconduction-mode boost converter with reduced reverse-recovery and switching losses. IEEE Trans. Ind. Electron., 50 (4) (2003), 767-776.

[48] Jovanovic, M.M.; Jang, Y.: State-of-the-art, single-phase, active power-factor-correction techniques for high-power applications an overview. IEEE Trans. Ind. Electron., 52 (3) (2005), 701-708.

[49] Mohan, N.; Undeland, T.M.; Robbins, W.P.: Power Electronics: Converters, Applications, and Design, 2nd ed., Hoboken, NJ: John Wiley \& Sons, Inc., 1995.

[50] Erickson, R.W.; Maksimovic, D.: Fundamentals of Power Electronics, 2nd ed., London, UK: Springer London Limited, 2001.

[51] Patterson, O.D.; Divan, D.M.: Pseudo-resonant full bridge DC/DC converter. IEEE Trans. Power Electron., 6 (4) (1991), 671-678.

[52] de Boeij, J.; Lomonova, E.; Duarte, J.; Vandenput, A.: Contactless energy transfer to a moving actuator, in Rec. 2006 IEEE Industry Applications Conf., Tampa, FL, 2006, vol. 4, 2020-2025.

[53] Lin, C.-S.; Lin, S.-G.; Chang, C.-F.; Li, H.-H.; Chen, T.-R.: Model of contactless power transfer system for linear track, in Proc. 2009 IEEE Int. Conf. Power Electronics and Drive Systems, Taipei, Taiwan, 2009, 1075-1079.

[54] van der Pijl, F.F.A.; Castilla, M.; Bauer, P.: Adaptive sliding-mode control for a multiple-user inductive power transfer system without need for communication. IEEE Trans. Ind. Electron., 60 (1) (2013), 271-279.

[55] Smeets, J.P.C.; Overboom, T.T.; Jansen, J.W.; Lomonova, E.A.: Modeling framework for contactless energy transfer systems for linear actuators. IEEE Trans. Ind. Electron., 60 (1) (2013), 391-399.
[56] de Boeij, J.; Lomonova, E.; Vandenput, A.: Contactless energy transfer to a moving load part I : topology synthesis and FEM simulation, in Proc. 2006 IEEE Int. Symp. Industrial Electronics, Montreal, Canada, 2006, 739-744.

[57] Papastergiou, K.D.; Macpherson, D.E.: Contact-less transfer of energy by means of a rotating transformer, in Proc. 2005 IEEE Int. Symp. Industrial Electronics, Dubrovnik, Croatia, 2005, 1735-1740.

[58] Smeets, J.P.C.; Encica, L.; Lomonova, E.a.: Comparison of winding topologies in a pot core rotating transformer, in Proc. 2010 IEEE 12th Int. Conf. Optimization of Electrical and Electronic Equipment, Brasov, Romania, 2010, 103-110.

[59] Madawala, U.K.; Thrimawithana, D.J.: A bidirectional inductive power interface for electric vehicles in V2 G systems. IEEE Trans. Ind. Electron., 58 (10) (2011), 4789-4796.

[6o] Bieler, T.; Perrottet, M.; Nguyen, V.; Perriard, Y.: Contactless power and information transmission. IEEE Trans. Ind. Appl., 38 (5) (2002), 1266-1272.

[61] Kawamura, A.; Ishioka, K.; Hirai, J.: Wireless transmission of power and information through one high-frequency resonant ac link inverter for robot manipulator applications. IEEE Trans. Ind. Appl., 32 (3) (1996), 503-508.

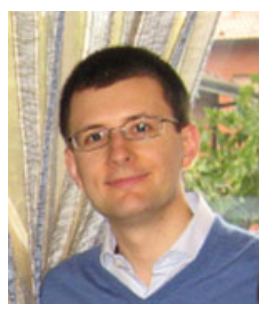

Riccardo Trevisan was born in Bologna, Italy, in 1987 . He received his B.Sc. and M.Sc. degrees in Electronics Engineering from the University of Bologna, Bologna, Italy, in 2009 and 2012, respectively. $\mathrm{He}$ is currently working toward the $\mathrm{Ph} . \mathrm{D}$. degree in Electronics, Telecommunications, and Information Technologies at the University of Bologna and IMA Industries, Italy, where he is full-time employed as a Ph.D. student. His main areas of interests include contactless energy transfer systems, wireless information transfer links, and power electronics oriented to industrial applications.

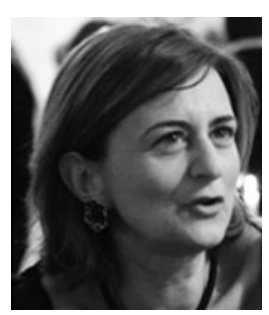

Alessandra Costanzo received a Doctoral degree in Electrical Engineering (magna cum laude) from the University of Bologna, Italy. Since 2001, she has been an Associate Professor of Electromagnetic fields at the University of Bologna, Polo di Cesena. She has co-authored more than 130 scientific publications on peer reviewed International Journals and conferences and three chapter books. She holds three international patents. Her research activities have focused on several topics such as: electro-thermal characterization and modeling of RF/ microwave nonlinear devices; simulation and design of active microwave-integrated circuits; broadband design of selfoscillating circuits and systems for electrical, stability, and noise performance. More recently, Professor Costanzo has worked on an innovative software platform for the nonlinear and electromagnetic co-simulation of RF systems, excited by modulated sources. She has demonstrated the circuit-level analysis of entire MIMO and UWB links, including realistic channel models. She is currently involved in the development of energy autonomous sensors based on wearable systems and energyharvesting technologies and in the development of wireless power transfer systems. Many are her research and industrial collaborations that have conducted to significant funding 
sources from both institutional and private investors. She is a member of the management committee of the recently approved EU COST action WiPE "Wireless power transfer for sustainable electronics". She is a member of the TPC board of the MTT-S IMS and of the EUMW and of the steering committee of the 2014 EUMW, which will be held in Italy. She is the Vice Chair of IEEE MTT-S TC-26 Wireless Energy Transfer and Conversion and member of IEEE MTT-S TC-24 RFID Technologies. She serves at the Editorial Board of many International Journals, such as IEEE-T-MTT, IEEE-T-CAD, IEEE MWGL, and IJMWT. She is an executive editor of the Cambridge University Press Wireless Power Transfer Journal. 